
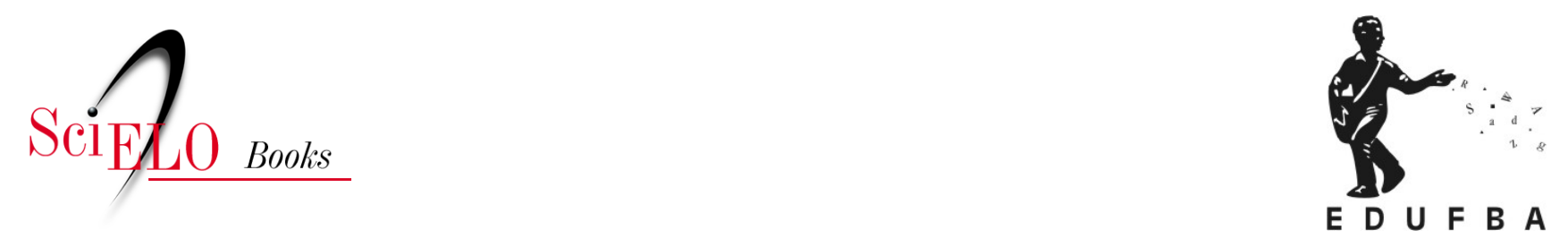

\title{
Além da etnografia olhares sobre o trabalho dos pesquisadores
}

\author{
Cristina Larrea Killinger
}

\section{SciELO Books / SciELO Livros / SciELO Libros}

KILLINGER, C.L. Além da etnografia: olhares sobre o trabalho dos pesquisadores. In: LIMA, M.A.G., FREITAS, M.C.S., PENA, P.G.L., and TRAD, S., orgs. Estudos de saúde, ambiente e trabalho: aspectos socioculturais [online]. Salvador: EDUFBA, 2017, pp. 191-202. ISBN: 978-85232-1864-5. http://doi.org/10.7476/9788523218645.0011

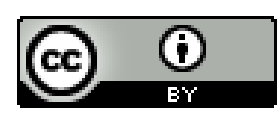

All the contents of this work, except where otherwise noted, is licensed under a Creative Commons Attribution $\underline{4.0 \text { International license. }}$

Todo o conteúdo deste trabalho, exceto quando houver ressalva, é publicado sob a licença Creative Commons Atribição 4.0. 


\section{Além da etnografia olhares sobre o trabalho dos pesquisadores}

\section{CRISTINA LARREA KILLINGER}

\section{Introdução}

Neste capítulo apresento uma reflexão compreensiva da experiência etnográfica com foco nas relações entre os sujeitos nativos e pesquisadores durante e depois do trabalho de campo. Trato de pensar sobre os olhares, interações e diálogos que outros têm sobre a nossa atividade para aprofundar nossos compromissos e responsabilidades com a etnografia, que inclui as pessoas de que fazem parte. Indago o modo de perceber o que eles pensam sobre nós, sujeitos que observamos, escutamos e compartilhamos espaços e tempos comuns.

A partir de uma leitura compreensiva, exploro os sentidos e os significados de ser pesquisador e da atividade de campo a partir de exemplos etnográficos concretos situados num contexto cultural, sociopolítico e econômico particular. Apresento espaços de diálogo que geram a intensidade da relação e faz com que os nativos interpelem os pesquisadores para mostrar seus pontos de vistas sobre as atividades de pesquisa e da natureza da relação que estabelecem com o etnógrafo.

\section{Compartilhar a relação de sentido}

Os etnógrafos tratam de interpretar o que pessoas de outras culturas expressam sobre o mundo vivido e buscam compreender o sentido das 
formas simbólicas da cultura. O que os nativos pensam, fazem e sentem afeta o nosso olhar sobre eles e a nossa compreensão do mundo. Apesar da experiência empática que Malinowski aludia para compreender a cultura a partir de saber se colocar no lugar do outro, a crítica de Geertz se centrava na questão da compreensão do problema cultural. Para saber interpretar outra cultura é insuficiente ser somente um etnógrafo empático. Os etnógrafos buscam entender o que os outros acreditam que são e o que opinam sobre nós. Trata-se, pois, de uma tarefa hermenêutica. (GEERTZ, 1994)

Nessa busca, este capítulo se centra na fusão de horizontes para compreender como os nativos colocam os etnógrafos no mundo deles a partir das relações intersubjetivas que entre eles se constroem durante a pesquisa de campo. O que significa para os nativos a nossa atividade de pesquisa, e de que modo eles integram esses conhecimentos, os discutem e os comparam? É possível que o nativo se aproprie do olhar antropológico? Quando e como o nativo coloca o antropólogo como sujeito?

Em resumo, a questão é compreender o que os nativos pensam sobre os antropólogos e o que estes fazem - anotar, pesquisar, colaborar - em um espaço simbólico e temporal concreto. $\mathrm{O}$ fazer dos etnógrafos em campo conforma práticas de socialização, as quais transformam e redefinem a identidade dos etnógrafos, conferindo uma plasticidade que se situa na dinâmica da relação.

Para ilustrar essa discussão de caráter experimental desde uma perspectiva compreensiva, (MARCUS; FISCHER, 2000) apresento três exemplos de experiências etnográficas diferentes desenvolvidas no estado da Bahia. A primeira pesquisa de campo foi realizada num bairro periférico da cidade de Salvador da Bahia. ${ }^{1}$ A segunda em uma comunidade quilombola na região do Baixo Sul. ${ }^{2} \mathrm{E}$ a última em uma comunidade pesqueira do município de Nilo Peçanha. ${ }^{3}$

1 Etnografia de longa duração integrada num projeto interdisciplinar de avaliação epidemiológica sobre a implantação de um programa de saneamento ambiental. Abarcou um período de 44 meses, entre os anos 1997 e 2010

2 Trabalho de pesquisa integrado num projeto epidemiológico que consistia em avaliar as condições de saúde da população marisqueira. A etnografia durou 15 meses, distribuídos em distintas etapas entre os anos 2006 e 2012 .

3 As duas primeiras comunidades formavam parte de uma pesquisa de campo na região de extremo sul sobre a transição dos estudantes à secundária educação universitária que abarcou um total de seis meses 
Agrupamos esses exemplos em três interações de maior intensidade etnográfica que intitulamos "compartilhando saberes", "ações" e "afetos". Este conjunto responde a um processo de reflexão metodológico cuja ênfase é colocada sobre diferentes olhares e no modo de compartilhar que sempre implica no tempo de saberes, ações e afetos. Trata-se de uma relação de sentido e de conhecimento. (VIVEIROS DE CASTRO, 2002)

Nestas dinâmicas interativas entre pesquisadores e nativos, a intensidade etnográfica tem um papel fundamental como catalisador nesse processo. Defino a intensidade como a:

Atitude metodológica onde a reflexividade e a emoção ganham maior força durante a pesquisa de campo, facilitando um melhor processo de compreensão dos fenômenos observados. Esta intensidade, caracterizada por ser dinâmica, diversa, e irregular flui melhor quando certos imponderáveis do trabalho e acontecimentos imprevisíveis chegam a ser mais relevantes que os acontecimentos cotidianos. Os imponderáveis aos que me refiro como exemplo para analisar a intensidade etnográfica pertencem ao conjunto de discursos reflexivos e emotivos produzidos pelos atores sociais em diálogo com o antropólogo a um nível compreensivo. (LARREA-KILLINGER, 2011, p. 11-12, tradução nossa)

Nas interações, os saberes, as ações e os afetos formam um elo inseparável. Para "saber" tem que atuar e ser afetado pelo que se está conhecendo, descobrindo e aprendendo. Da mesma maneira, para "atuar", a pessoa parte do habitus e das emoções. Os "afetos" se desenvolvem com o "saber" e no mundo das ações cotidianas, apesar de que podem ganhar mais intensidade e força em situações imponderáveis durante a pesquisa de campo.

\section{Compartilhando saberes}

Durante o trabalho de campo nativos e etnógrafos estão inseridos em um mundo de relações em que olhares, interações e diálogos fazem par-

entre 2013 e 2014. No município de Nilo Peçanha, a comunidade de São Francisco foi escolhida porque as pessoas guardavam relações de parentesco com as que moravam na comunidade quilombola da segunda etnografia referida. Compararam-se as condições de saúde da população marisqueira e pesqueira, num total de quatro meses de pesquisa entre 2014 e 2015 
te da dinâmica do cotidiano. O que acontece é que em determinadas situações os nativos interpelam aos pesquisadores atuando como observadores do fazer do etnógrafo. Neste momento se inicia um diálogo sobre a natureza da pesquisa que motiva o etnógrafo a aprofundar sobre os limites do método e as formas de representação do que ele pretende fazer com os resultados de suas observações. O etnógrafo trata de compreender o significado subjetivo de suas ações no diálogo com o outro. Trata-se de uma relação intersubjetiva. (SCHÜTZ, 20oo) Neste caso, as ações que incluem esta relação partem do ato de escrever, anotar e registrar as observações na pesquisa de campo.

O exemplo que apresento tem a ver com uma situação imponderável situada na comunidade quilombola do Baixo Sul da Bahia, onde fui acolhida pela primeira vez pela família da presidenta da associação de moradores em 2006. Compartilhava um quarto com uma das suas filhas e um dos filhos, numa comunidade de 120 pessoas. As casas eram na sua maioria de taipa e estavam distribuídas em três caminhos de areia. Moravam em unidades domésticas nucleares, mas guardavam relações de parentesco entre todas elas. A maioria dos adultos com mais de 30 anos não sabia ler nem escrever, e os jovens de mais de 15 anos tinham deixado a escola sem concluir o ensino fundamental. Somente eram as crianças e as meninas jovens que estudavam na escolinha da comunidade ou em escolas de nível primário e secundário em comunidades vizinhas.

Quando fui morar na comunidade comecei a visitar as casas com o fim de estabelecer os primeiros contatos com os adultos. A excessiva timidez e desconfiança, mesmo tendo sido convidada pela comadre da presidenta e ser aceita na celebração da assembleia da associação, impedia estabelecer uma relação fluída entre todos nós. Após várias visitas às famílias, percebi que continuavam incomodadas com a minha presença e observei que não gostavam de conversar e responder perguntas. Decidi aguardar que fossem elas que iniciassem as conversas e que se aproximassem de mim. Visitei-as menos para ganhar maior confiança e fiquei aguardando no terreno da presidenta onde havia um pequeno quiosque com mesas e bancas, no qual nos fins de semanas os parentes e pessoas de outras comunidades se encontravam para se divertir com bebidas e danças. A casa da presidenta da associação era muito frequentada por adultos e crianças porque havia um pequeno comércio no qual compravam produtos básicos de consumo. Aliás, as mulheres eram as que mais 
frequentavam este local porque havia uma fonte que usavam duas vezes por dia para coletar água.

$\mathrm{O}$ fato de haver decidido aguardar as pessoas a se aproximarem foi a melhor opção para propiciar um diálogo. Aprendi a fazer observação em silêncio. Observei que o silêncio era valorizado na comunidade, na rotina do cotidiano, e que as conversas e gargalhadas eram propiciadas com o trago de bebida alcoólica - cachaça e cerveja -, a dança e a música própria do descanso do fim de semana.

Tempos depois, compreendi que elas não estavam acostumadas a conversar com pessoas "estranhas" dentro da casa. O lugar público para conversar era o quiosque ou nos terrenos dos fundos das casas onde se comentavam os problemas. Elas conversavam pouco quando faltava cerveja, cachaça e música. Percebi que ao fazer indagações sem ser parente, e não ter intimidade, poderia ser classificada como "fofoqueira" e por isso ser rejeitada. Não há pior insulto que esse no lugar.

$\mathrm{Na}$ posição de observadora silenciosa, as mulheres carregando baldes na cabeça olhavam para mim enquanto passavam por atrás do quiosque em direção à fonte. As crianças foram as únicas que se aproximaram e sentaram-se ao meu lado, enquanto eu fazia anotações. No dia que decidiram fazer isso, uma das meninas pediu uma folha do meu caderno e uma caneta para desenhar. Imediatamente o resto do grupo imitou o mesmo pedido e o meu caderno de anotações se transformou em desenhos que as crianças me entregaram com as observações do mundo deles. Dialogamos através de folhas de papel, desenhos e anotações.

Essa atividade se prolongou como uma brincadeira. A minha atividade de escritura era compartilhada pelo interesse das crianças em me obsequiar com desenhos de casas, árvores e pássaros bem coloridos com o nome de autoria embaixo. Tratava-se de uma atividade voraz e competitiva entre eles para me agradar e chamar a minha atenção. Com o decorrer dos dias as folhas acabaram, então sugeri que pintassem mais os desenhos, com os lápis de cor que os presenteei. Surpreendia-me a rapidez com que pediam folhas de papel e me devolviam seus desenhos. E um dia perguntei por que desenhavam tão rápido. Uma das crianças me respondeu que desenhavam na mesma velocidade que eu escrevia no meu caderno. Várias crianças disseram querer usar as cores na mesma velocidade que eu usava a minha caneta, pois se eu anotava muitas coisas eles desejavam me mostrar muitas coisas. Para dialogar comigo tratavam de me imitar. 
A troca de nossos mundos consistia em mostrar a minha caligrafia e ler palavras do meu caderno, algumas das quais achavam divertidas. Por enquanto eles me entregavam desenhos de pássaros, flores e árvores, escrevendo o meu nome adornado com corações e palavras de carinho. Mais tarde, essa dinâmica de diálogo passou a outro plano. Queriam que lhes ensinasse canções e jogos infantis do meu mundo. Aprendi a traduzi-las e a brincar com eles.

Essa experiência começou a ser enxergada com curiosidade pelas mães. A presidenta da associação me pediu que durante a semana se desse aulas à tarde para as crianças, quando voltassem da escola, aos jovens que haviam deixado a escola, e aos adultos que não sabiam ler nem escrever. $O$ fato de me converter em uma "professora” facilitou a minha aceitação como membro da comunidade. Com esta atribuição, as mulheres começaram a conversar comigo. $\mathrm{O}$ meu interesse por iniciar temas de conversas relacionados com o objetivo da pesquisa e de visitá-las na casa delas começaram a ser bem aceitas.

Conversar sobre "pesquisa" fazia sentido nas atividades escolares. Esse termo era conhecido pelas crianças e também pelas mães. Quando as crianças chegavam em casa diziam que as professoras haviam solicitado pesquisar algum assunto no livro, procurar na internet, na escola ou perguntar na comunidade. $\mathrm{O}$ mundo da pesquisa estava relacionado com o conhecimento e o uso da tecnologia. Eu fazia parte desse mundo de fora. Nessa troca compartilhávamos saberes que tinham sentido, como processo de intercambio. Aprendi a evitar as perguntas diretas, consideradas como falta de respeito, a escutar, a sentir e aprender com curiosidade as atividades do cotidiano.

No curso dos jovens que haviam abandonado a escola, o processo foi parecido. Interessada no método de alfabetização de Paulo Freire, decidi aplicar uma série de aulas informais em que os jovens escolheram como assunto gerador um tema da natureza. Todas as leituras se centraram em falar da natureza ao redor e compará-la a outras regiões brasileiras. Procurei livros de biologia emprestados da biblioteca situada no povoado vizinho e ao mostrá-los se interessaram em comparar as espécies de animais. Quando souberam de que eu tinha uma câmara fotográfica solicitaram, como uma das práticas, fotografar a natureza da ilha onde moravam. Ninguém naquela época tinha câmera e telefone celular, o que despertou muita curiosidade poder fotografar o mato e o mangue. Da natureza, o principal mundo fotografado foi o dos pássaros, espécies selvagens que consideravam mais pró- 
ximas ao reino humano. Quando fotografei animais e os lugares de morada como as árvores, os ninhos e os buracos, sempre eu estava em companhia das crianças e jovens. Seguindo em ordem de importância foram fotografados também os animais que asseguravam o sustento diário, como diversas espécies de mariscos e animais de caça. Nas explicações que deram sobre essas fotografias centraram o debate na comparação entre o comportamento dos humanos e dos animais. $\mathrm{O}$ animal do mato mais humanizado foi o pássaro, este que as pessoas gostavam de pegar do ninho e criar como um filho.

As crianças preferiram fotografar o movimento. As brincadeiras como: dançar, pular, correr ou subir em árvores, foram considerados os desafios mais importantes. Exemplo de crianças subindo árvores enormes e compridas, ou correndo para desafiar o foco da câmera, desafiava a destreza do fotógrafo. Deixei que fossem as crianças as que fotografassem as cenas de que mais gostassem. Preferiam fotografar os animais em liberdade e não os presos em gaiolas como os pássaros, ou os amarrados como os cachorros. As crianças escolhiam ser o centro da imagem sempre em grupo e acompanhados de cenas onde dominavam as árvores, flores e animais de estimação fora da casa.

Um ano depois, quando retornei a campo, uma jovem havia comprado uma câmera, e aos poucos foi se introduzindo o uso do telefone celular. A mesma jovem continuou com os cursos de reforço escolar para as crianças e depois se transformou em fotógrafa de festas e eventos da comunidade. No dia da inauguração da construção da associação, ela fez fotografias assim como no dia da festa de São Cosme e São Damião. Além de fotografar pela primeira vez a mãe quando incorporou os santos caboclos, entregou mais tarde uma cópia digital para mim do que havia fotografado para compartilhar comigo o que para ela era o seu mundo. Naquela época, ela havia terminado o ensino médio e estava pensando em fazer faculdade.

\section{Compartilhando ações}

Trata-se do processo de observação que os nativos fazem sobre os projetos de pesquisa-ação e dinâmicas participativas de projetos universitários ou de ONGs. Os nativos comparam diferentes estilos de pesquisa e participação e adotam determinadas posições diante dos pesquisadores e opiniões sobre as pesquisas. Relações de poder e tensões sociais se desencadeiam 
entre os nativos que buscam determinado reconhecimento entre os pesquisadores em etapas de maior visibilidade da pesquisa, como é o processo de transferência do conhecimento.

O seguinte exemplo etnográfico se situa no bairro periférico de Salvador na Bahia. Em 2007, iniciou-se a última etapa da pesquisa dez anos depois com a elaboração de um documentário em vídeo sobre as condições de saneamento solicitado pelos moradores do bairro. A filmagem foi finalizada em um mês com o apoio de muitos moradores e de uma ajudante de câmera. Não houve recursos econômicos para a filmagem nem para a edição, sendo que o custo assumido por mim a ajudante de câmera durante a produção e por um amigo. $\mathrm{O}$ objetivo foi de compartilhar com os nativos os resultados da pesquisa e disponibilizá-los para fortalecer os processos participativos e assim iniciar demandas à prefeitura municipal para as melhorias no bairro.

O processo de elaboração do documentário foi colaborativo, pois incluiu a tomada de decisões do roteiro por parte dos entrevistados e uma visualização prévia da primeira edição um ano depois. Os moradores se implicaram durante a filmagem, acompanhando-nos das casas e nas principais localizações do bairro, evitando assim os riscos de assalto pelo transporte da câmera. Também se responsabilizaram em guardar a câmera à noite e em facilitar moradia e apoio durante as entrevistas.

O imponderável, que levou a questionar este processo, aconteceu uma semana depois da gravação, quando uma das lideranças do bairro que eu conhecia há anos comentou a uma das minhas principais informantes que estávamos elaborando a filmagem ilegalmente por não ter solicitado aos entrevistados a permissão de suas imagens. Chamou-me a atenção que a liderança reclamasse esse documento quando a nossa intenção com o documentário não era passá-lo pela televisão, ou circulá-lo por festivais, mas bem se tratava do cumprimento de um pedido colaborativo para compartilhar os resultados da pesquisa com as pessoas do bairro. Para nós não era preciso esse documento, pois já contávamos com o atestado do comitê de ética da pesquisa desde 1997 e, sobretudo, porque se tratava de um pedido da comunidade.

A minha informante me recomendou que fosse pessoalmente à reunião da associação de moradores para apresentar a proposta de documentário e, desse modo, evitar que se espalhasse na rua que nós estávamos nos aproveitando dessa filmagem para "ganhar dinheiro". 
A minha informante insistiu que elaborássemos o documento de direitos de imagem para evitar problemas. Algumas pessoas do bairro não confiavam na liderança que estava à frente da associação. A liderança tinha uma fraca coesão interna no bairro, mas mantinha fortes conexões com lideranças políticas e representantes de uma ONG de fora do bairro. Exigia uma formalização para a filmagem que parecia inicialmente desnecessária para minha equipe e para os moradores do bairro, porque a produção do documentário se baseava na confiança e em um pedido da comunidade. Mas se converteu em uma exigência que os moradores consideraram como medida de proteção contra as possíveis más intenções da liderança.

Com este exemplo, observamos que a liderança tinha uma visão distinta sobre as exigências legais no processo de elaboração do documentário. Um processo colaborativo que partia de uma experiência etnográfica foi reduzido a um processo participativo formalizado, que exigia protocolos bem conhecidos por esta liderança e desnecessários para essa experiência.

Depois compreendi que a formalização do processo era necessária para evitar a confrontação interna entre algumas pessoas do bairro e a liderança, sobretudo para não suspender a produção. A cessão de direitos de imagem foi um documento incluído, uma vez iniciada a filmagem sem problemas por parte dos entrevistados. Esse imponderável me levou a refletir sobre a variedade de processos participativos e as tensões internas que poderiam ter aflorado caso se confrontasse a opinião da liderança com a dos moradores.

\section{Compartilhando afetos}

Trata-se de mergulhar na implicação de afetos e emoções entre informantes e pesquisadores durante e depois da pesquisa de campo. A construção dos afetos sofre etapas de maior ou menor intensificação entre pessoas, $\mathrm{e}$ momentos concretos que podem levar a demandas complexas com risco ao comprometimento de pesquisa e da própria identidade do pesquisador. Indago mais sobre contextos de maior proximidade e intimidade do que sobre regras de hospitalidade próprias da convivência.

Este último exemplo etnográfico se situa no município de Nilo Peçanha, em 2013. Quanto maior era o tempo de convívio e de aceitação na comunidade, maior era a possibilidade de sofrer os mesmos perigos e riscos. $\mathrm{O}$ imponderável aconteceu um dia em que, estando na casa de uma marisqueira 
e do primo dela colaborando no processo de catação de caranguejo, a visita de uma vizinha provocou um problema de "mau olhado".

Na casa de Marta, e em companhia do primo, ficamos um sábado à tarde, catando caranguejo, sentados no chão diante de um balde de plástico, conversando e escutando música, quando entrou uma vizinha. A senhora Teresa ficou admirada ao ver como eu batia com um pauzinho a casca das pernas dos caranguejos e extraia com os dedos a carne. Com pouca habilidade, mas com paciência, eu imitava os movimentos de Marta. Queria aprender o trabalho de catador e compartilhar um sábado à tarde com ela e o seu primo que também nos ajudava nessa tarefa.

Dona Teresa começou a falar bem de mim, de como se admirava que uma "branca estrangeira" fizesse esse trabalho que muitas jovens evitavam, como, por exemplo, as próprias netas. Antes de se aposentar trabalhou muito como marisqueira e se queixou da hipertensão, das dores nas mãos, nos braços e nos joelhos como consequência dessa atividade. As queixas sobre o próprio corpo eram amenizadas com o valor atribuído à venda do catado para ajudar na sobrevivência da família.

Quando Teresa saiu da sala, comecei a bocejar e a me sentir cansada e fraca. Marta e o primo dela observaram o meu decaimento e começaram a falar entre eles que a senhora Teresa me havia provocado o "mau olhado" por excesso de adulação e admiração. A inveja involuntária era perigosa e signo inequívoco do mau olhado, e por isso Marta e o primo decidiram que deixasse de catar caranguejo e me deitasse no sofá.

Diante dessa constatação do mau olhado começaram a dar gargalhadas. Marta e o primo não pararam de rir ao ver que sendo branca e estrangeira também podia ser afetada pelo olho de uma pessoa do lugar. Decidiram que deveriam me levar a uma rezadeira. Mas pela manhã havia melhorado, indicaram-me um banho de folhas do mato. Um banho de "descarga", ou descarrego, para me proteger da possibilidade de reaparecer o "olhado". $\mathrm{O}$ primo me recomendou colocar um dente de alho no bolso sempre que saísse de casa para evitar o mal.

Tanto Marta quanto o primo constataram a minha vulnerabilidade diante de problemas comuns como o olhado. Apesar de saber que os brancos e estrangeiros não acreditavam nessas crenças, no fundo se sentiam contentes de haver comprovado que o risco da inveja afetava a outras pessoas que não eram da comunidade. Reconheciam que os brancos - médicos, técnicos 
e pesquisadores - não consideravam suas crenças como condicionantes de problemas de saúde. Preferiam não falar desses assuntos durante as visitas de pesquisadores ou técnicos, para não escutarem piadas contra suas crenças. Eles se perguntavam por que me haviam afetado desse modo. E a resposta mais convincente para eles é que eu compartilhava de suas crenças, por isso podia sentir.

A aceitação na comunidade passou a outro plano mais profundo por ser alvo dos mesmos riscos, já que para eles simbolicamente compartilhava as mesmas crenças. Segundo eles, isso me capacitava para poder compartilhar a mesma eficácia simbólica no processo de cura. Os banhos de descarga e fechamento do corpo passaram a ocupar outra das práticas de integração a uma cultura. $\mathrm{O}$ sentido de pertença não passava somente por dominar uma língua e apreender habilidades técnicas, mas também a sofrer processos de adoecimento e compartilhar perigos simbólicos.

\section{Um modo de conclusão}

Os exemplos ilustram parte do jogo de sentidos na relação entre nativos e antropólogos, em que o discurso nativo e o antropológico se confundem. O antropólogo deixa de ser etnógrafo porque a identidade é confusa ou por ter entrado em crise para o olhar nativo, e este, o nativo, se apropria de uma visão crítica do fazer do etnógrafo. Nessa fusão de horizontes, o sujeito nativo se revela como sujeito que dialoga a um nível mais simétrico. (VIVEIROS DE CASTRO, 2002) O nativo está menos sujeito ao discurso do antropólogo e mais liberado para penetrar nos procedimentos do etnógrafo. O nativo interpela ativamente o antropólogo. Na estrutura pré dada da relação se percebe uma alternância em que observamos o nativo mais antropólogo e o etnógrafo mais nativo. Essas possibilidades do jogo no campo são temporárias e situadas num contexto particular.

$\mathrm{O}$ fato de se basear em exemplos permite abrir uma reflexão sobre os imponderáveis no campo e a plasticidade das relações. O antropólogo chega a ser mais nativo (TEDLOCK, 1991) com o último exemplo, e o nativo mais antropólogo nos outros exemplos. Assim, ao dialogar de modo mais interativo, antropólogos e nativos conseguem construir pontes mais simétricas e humanas. 


\section{Referências}

GEERTZ, C. Conocimiento local: ensayos sobre la interpretación de las culturas. Barcelona: Paidós Ibérica, 1994.

LARREA-KILLINGER, C. Intensidad etnográfica: reflexividad y emoción en el trabajo de campo. Ankulegi, Donostia, n. 15, p. 11-22, 2011.

MARCUS, G.; FISCHER, M. J. La antropología como crítica cultural: un momento experimental en las ciencias humanas. Buenos Aires: Amorrortu, 2000.

SCHÜTZ, A. La construcción significativa del mundo social: introducción a la sociología comprensiva. Barcelona: Paidós Ibérica, 2000.

TEDLOCK, B. From participant observation to the observation of participation: the emergence of narrative ethnography. Journal of Anthropological Research, Chicago, v. 47, n. 1, p. 69-94, 1991.

VIVEIROS DE CASTRO, E. O nativo relativo. Mana, Rio de Janeiro, v. 8, n. 11, p. $113-148$, abr. 2002. 